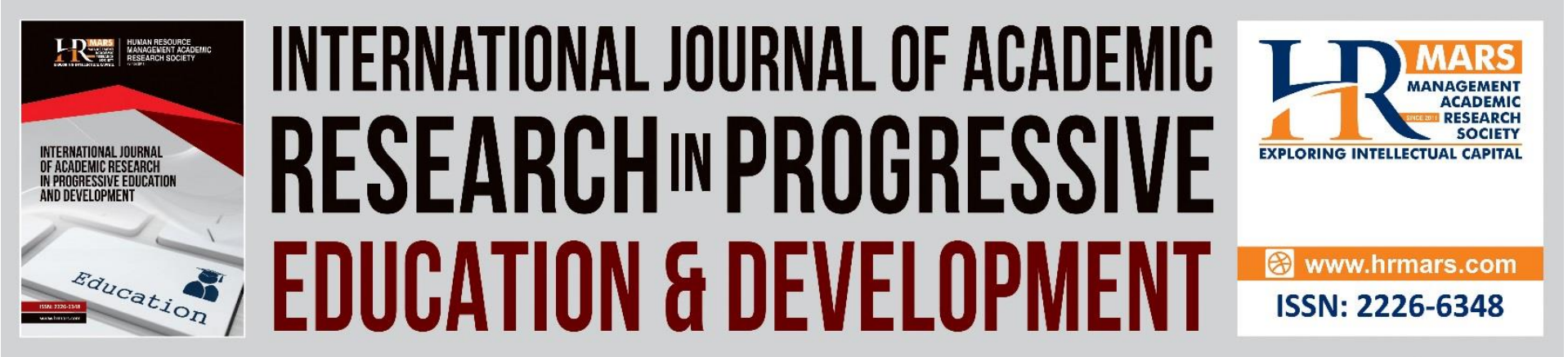

\title{
Industries and Vocational Training Centres Partnership: Issues and Improvement Plan
}

Hayadi Mustafa, Mohd Azlan Mohammad Hussain, Rafeizah Mohd Zulkifli

To Link this Article: http://dx.doi.org/10.6007/IJARPED/v11-i1/11959

DOI:10.6007/IJARPED/v11-i1/11959

Received: 09 November 2021, Revised: 14 December 2021, Accepted: 27 December 2021

Published Online: 13 January 2022

In-Text Citation: (Mustafa et al., 2022)

To Cite this Article: Mustafa, H., Hussain, M. A. M., \& Zulkifli, R. M. (2022). Industries and Vocational Training Centres Partnership: Issues and Improvement Plan. International Journal of Academic Research in Progressive Education and Development, 11(1), 134-144.

Copyright: (C) 2022 The Author(s)

Published by Human Resource Management Academic Research Society (www.hrmars.com)

This article is published under the Creative Commons Attribution (CC BY 4.0) license. Anyone may reproduce, distribute, translate and create derivative works of this article (for both commercial and non-commercial purposes), subject to full attribution to the original publication and authors. The full terms of this license may be seen

at: http://creativecommons.org/licences/by/4.0/legalcode

Vol. 11(1) 2022, Pg. 134 - 144

http://hrmars.com/index.php/pages/detail/IJARPED

JOURNAL HOMEPAGE

Full Terms \& Conditions of access and use can be found at http://hrmars.com/index.php/pages/detail/publication-ethics 


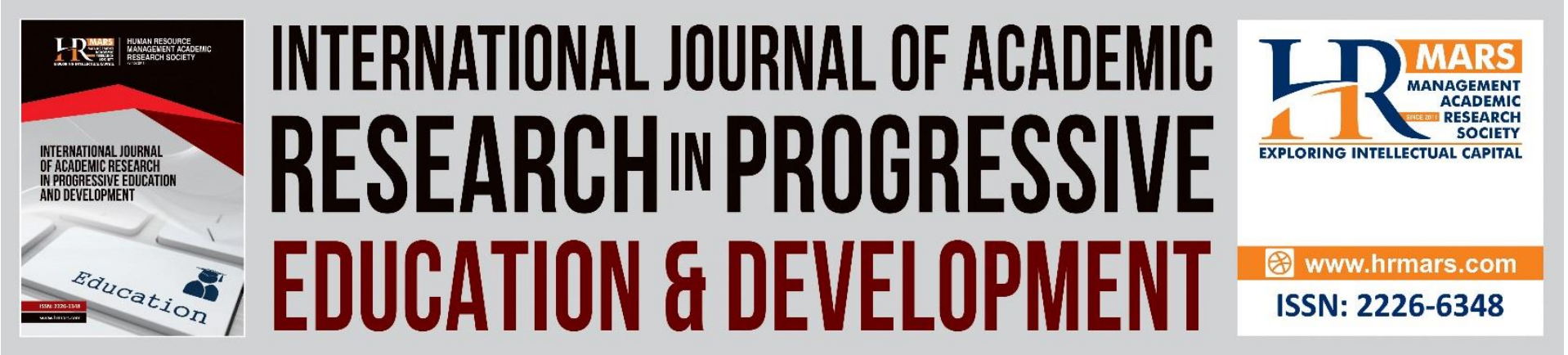

\title{
Industries and Vocational Training Centres Partnership: Issues and Improvement Plan
}

\author{
Hayadi Mustafa \\ Universiti Pendidikan Sultan Idris \& Kolej Kemahiran Tinggi MARA \\ Email: hayadi@mara.gov.my
}

\author{
Mohd Azlan Mohammad Hussain (Corresponding Author) \\ Universiti Pendidikan Sultan Idris \\ Email: azlan_hussain@ftv.upsi.edu.my \\ Rafeizah Mohd Zulkifli \\ Universiti Pendidikan Sultan Idris \\ Email: rafeizah@ftv.upsi.edu.my
}

\begin{abstract}
Several challenges have been found to develop and sustain collaboration between industries and vocational institutions, including funds, misunderstanding of objectives, policy limitation, and bureaucracy. This paper systematically reviewed five journals regarding the issues in collaboration between industries and vocational institutions, then identified a possible solution to improve that collaboration. A meta-analysis reviewed conducted on five related journals and research papers concerning cooperative relations vocational institutions with industries published within five years of this paper being produced from Emerald, EBSCOhost, ProQuest, and Sage Publication database sources. This study also found that collaboration between industries and vocational training centers can be improved if the government provides a clear policy to enhance mutual understanding between both parties. This approach can be used as a reference for Vocational institutions to strengthen the quality of vocational graduates by turning them into job-ready workers.
\end{abstract}

Keywords: Industrial-TVET Partnership, Malaysian TVET, Meta-analysis, Vocational Education in Malaysia, Industrial Collaboration

\section{Introduction}

A win-win situation is one of the foundations for successful partnerships between the education sector and industry. The collaboration between industries and training centers is essential to fulfilling the objective of vocational education to develop a job-ready graduate. Many benefits will be obtained from the cooperation between both parties, such as exposure latest technology to students in training centers more effectively and producing skilled workers to meet the industry requirement (Raihan, 2014). The education sector is also a 
significant source of economic growth for a country to reach the status to become a developed country (ElObeidy, 2016) (Abu-Hamatteh et al., 2008). Both educational institutions and industries need each other to produce skilled workers, whereas educational institutions produce skilled graduates while industry needs skilled workers. In addition, technological advances growth rapidly, which influences the development of the national economy. The world has agreed on the need for investment through education to gain highquality human resources (Obwoge et al., 2013). Thus, collaborative vocational institutions and industries are crucial to develop skilled graduates in line with industrial demand (Ashari \& Rasul, 2014). In short, a collaboration between industries and Vocational centers is a medium to achieve mutual benefits among both parties (Asnorhisham, 2015). Hence, government support is needed to monitor the quality of collaboration between TVET institutions and industry. Government support can be done through giving recognition, accreditation, and monitoring curriculum development. (Miglani, 2018). However, some issues have been identified in collaboration between vocational institutions and industry, including funds, time constraints, lack of technology and facilities, lack of expertise, bureaucracy, and confidentiality of companies.

This study aims to identify the importance of collaboration between Vocational institutions and industry, issues in implementing the collaboration, and strategies to enhance existing cooperative relationships. This formulation can benefit the development of research on collaboration between Vocational institutions and industry.

\section{Collaboration of Vocational Institutions - Industry}

In the industry 4.0 era, the latest skills and technology development are needed to ensure the success of a Vocational Institution to produce highly skilled students to meet industry demands. The collaborative program between industries and training centers is a mechanism in developing and strengthening the vocational education system, especially in producing a job-ready vocational graduate. This collaboration needs to be implemented to empower vocational students' skills in technology and increase student employability.

The collaborative program between industries and vocational institutions can be conducted in several strategies. For example, the placement of vocational teachers in the industry provides teachers with better exposure to current technological advances (Nordin, Hassan, \& Ismail, 2014). Industries' activity and skill demands are changing so rapidly that it is an enormous task for vocational teachers to simply keep on top of these developments (Zulkifli et al., 2018). The experience gathered during the industrial placement period will be valuable for teachers because it can be shared with their students, especially regarding advanced and sophisticated equipment used by industries in the real job setting. Similarly, the placement of industrial workers in vocational institutions as part-time teachers for a particular curriculum can deliver a good experience and knowledge to students (Krishnamurthy, VandeCreek \& Kaslow, 2004). In the meantime, it can further strengthen the relationship between the Vocational institutions and the industry as well as attract other industry sectors to the program.

Various programs have been implemented in Asian countries to foster collaboration between institutions and industries. Among the collaborative structure methods implemented is creating a flexible training system for both parties depending on the time and location of the training (Ashari \& Rasul, 2014). For example, the industry conduct training 
using facilities provided by any vocational institution at the time agreed upon by both parties. Likewise, students of vocational institutions can practice with the latest technology in the industry. These flexible training systems provide students and industrial workers access to quality training materials and facilities. An open and continuous direct communication between both parties is also critical to exchange information clearly without delays and misunderstandings (Ashari \& Rasul, 2014). The learning delivery method also must be structured to ensure the quality and positive impact of the training programs. In the meantime, experienced coaches or instructors from the industry are necessary to train students to embrace the current technology.

Various collaboration programs have been implemented in Malaysia to strengthen the collaborative relationship between industry and vocational institutions and produce graduates who meet industry demand (Ashari \& Rasul, 2014). The Malaysia Ministry of Human Resources has introduced programs such as the Skills Malaysia Partnership (SMP) to develop and promote collaboration between vocational institutions and industries. The National Dual Training System (NDTS) program by the Malaysia Ministry of Human Resources also positively encourages collaboration between industry and vocational institutions. The NTDS program was implemented in 2005 to develop knowledge and skills for youth and industrial workers (Adam et al., 2017). NDTS is two-dimensional learning using the concepts of placing students in industries such as industrial training that can provide and enhance theory and skills knowledge.

Collaboration between industry and vocational institutions can also reduce the inefficiency of industry demand for graduates, improve skilled workers, and provide theoretical knowledge from Vocational institutions to industry workers. The partnership will also create vocational institutions' awareness of job opportunities and demands to train students to be more relevant for the job market. In return, the industry will have opportunities to use the research and training infrastructure available at the institution for up-skilling and re-skilling their workers. At the same time, it can implement a dual learning program system where students and industry workers can gain knowledge and experience in theory and practice. Students' exposure to real-time employment is also an interest of collaboration with industries to enhance students' opportunities in pursuing employment after graduating (Moses, 2016).

\section{Method of Study}

This study uses a systematic literature review method through a meta-analysis approach. The approach of meta-analysis methods has been used according to the researcher's objective. Meta-analysis is an effective method for formulations, especially in research (Forero, LopezLeon, González-Giraldo, \& Bagos, 2019). This method will provide valuable new information by unifying information published in the previous report. In this study, the data have been obtained by reviewing five journals and research papers concerning cooperative relations vocational institutions with industries published within five years of this paper being produced retrieved from Emerald, EBSCOhost, ProQuest, and Sage Publication database sources. Some other journals are also referred to for more detailed information for this study. Two main themes have been used to guide selecting, organizing, and reflecting the data from those journals, including "issues" and "improvement plan." This paper also used descriptive 
DEVELOPMENT

Vol. 11, No. 1, 2022, E-ISSN: 2226-6348 @ 2022 HRMARS

data to analyze the issues found in all five journals reviewed regarding securing and sustaining the win-win partnership between industries and training centers.

\section{Issues in Collaborations between Industries and Vocational Institution}

The cooperation between the institutions and the industry requires a good understanding between the two parties. It is very important to achieve success in a planned program. Problems or challenges often occur in every program, especially involving two or more parties. However, these problems and difficulties can be overcome or mitigated if each party has a mutual understanding to achieve cooperation objectives. From the study, there are various problems and challenges faced by some countries to facilitate cooperation for skills development, job opportunities, and curriculum development with the industry. The problems arise from both sides and need to be examined in detail, especially factors contributing to these challenges.

Among the main challenges in developing collaboration between industry and vocational institutions is finding the mutual benefits and understanding between both parties. Although some plans and programs have been created for this kind of collaboration, the win-win collaboration has not been fully implemented (Purnamawati \& Syahrul, 2018). Most implemented programs focused only on industrial training, mandatory for every vocational student (Ashari \& Rasul, 2014). Although an industrial training program benefits students and vocational institutions, some industries do not receive any profits from these activities but will have additional responsibilities to train them in their facilities.

Finding a mutual understanding is another issue that commonly arises in securing and sustaining collaboration between industries and vocational training centers. Some industries are not interested in establishing collaboration with the vocational institution since several terms and conditions are difficult to understand, especially regarding their goals and benefits. There is also a lack of visitation or invitation from vocational institutions to explain and attract them to collaborate (Ashari \& Rasul, 2014). Industries were also not fully aware of the advantages or benefits of collaboration with vocational institutions such as learning tools, infrastructure, and research and development opportunities. There is a lack of industry's interest in the partnership by refining the engagement of profitability from the win-win situation (or) by creating win-win situations. Furthermore, the staffing needed to administer and implement the collaboration plan and activities is burdensome responsibility to some industries (Adam et al., 2017).

Different cultures between the education system and the industry are also issues in industrial and educational institution collaborations (Asnorhisham, 2015). The desire to work together is less popular in the industry than in educational institutions. The working culture and environment in industrial are more toward profits oriented while educational institutions more focus on knowledge sharing and human development. The study found that most partnerships are not appropriately implemented because the collaboration will benefit one side only (Purnamawati \& Syahrul, 2018). For example, an under-job trainer is not exposed to company intelligence and technology optimally. Industry executes their productivity without exposing educators to the latest technology and knowledge they already have because they fear that information will leak to their competitors. There is also a challenge where the 
industry lacks voluntary personnel to become instructors who can share skills and technology with Vocational institutions.

(Ashari \& Rasul, 2014) their study found that out of 96 companies, $82 \%$ of them are not interested in collaborating with vocational training institutions because it has no impact on their company. $5 \%$ stated that there are complicated procedures and rules. $4 \%$ of the companies indicated bureaucracy problems and limited information on the cooperation program as reasons for their lack of interest. The study also found that 145 companies collaborating with vocational training institutions expressed concern about the partnership's sustainability. The financial problems have been identified as a significant issue as some companies have difficulty spending their budget to achieve the collaboration objective. In addition, they also have time constraints to provide training for Vocational institution instructors or students as having been promised in the collaboration agreement (Ashari \& Rasul, 2014). Usually, supervisors are busy with their daily tasks, such as preparing work procedures, giving job orders, and monitoring their production. Personal issues are also one of the concerns faced by industries. Some documents, technologies, or agreements cannot be disclosed to others, especially trainee workers, to avoid the company's secrecy being leaked to their competitors. Figure 1 below illustrates six common factors that make the industry stand out from collaboration with vocational training centers.

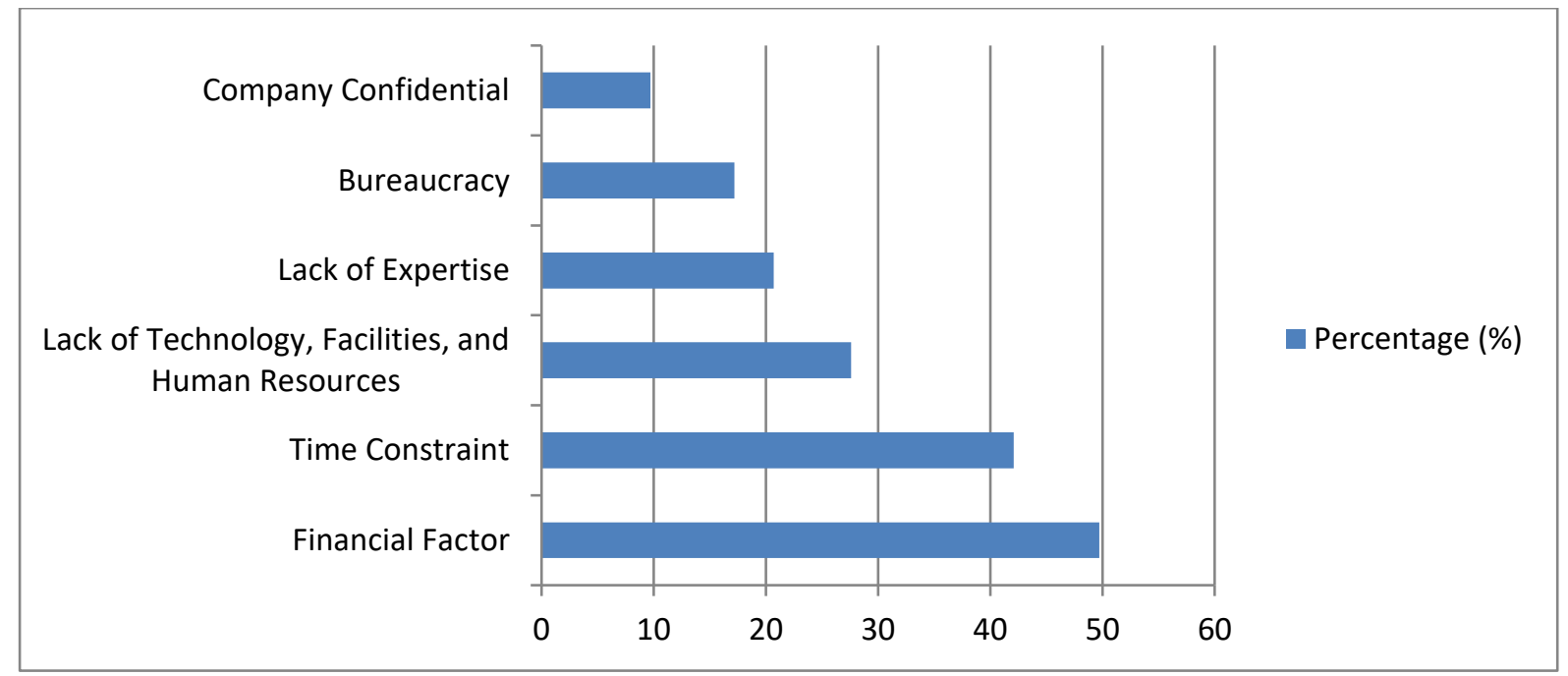

Figure 1: Description of Industry's Major Constraints (Ashari \& Rasul, 2014)

Studies also mentioned that establishing partnerships between the institutions and the industry was difficult to implement successfully since there is no sustainable government policy regarding cooperation between the institutions and industries (Obwoge et al., 2013). The government has a wide range of approaches, but they are not well implemented. Education and industry institutions face limitations in obtaining information on processes, technologies, job preparations, high technology tools, and responsibilities. Students undergoing industrial training are also not fully engaged in sharing this technology. Several collaborative activities on sharing materials, tools, and technologies in industrial training programs are not well implemented (Purnamawati \& Syahrul, 2018). The government should develop an approach to ensure that all programs or collaborations established run well and do not stray from its objectives (Miglani, 2018). 
DEVELOPMENT

Vol. 11 , No. 1, 2022, E-ISSN: 2226-6348 @ 2022 HRMARS

\section{Improvement of Collaboration}

Education is one of the critical things for a country's economic growth. Therefore, education development needs to be well evaluated to produce quality graduates. In order to realize this goal, a collaboration between vocational institutions and industry is required. Various collaboration programs have been established, but some areas need improvement.

The essential things in developing skills-based education are financial allocation, learning tools, and the industry's commitments (Ashari \& Rasul, 2014). The industry's role is crucial to channel information on the latest technology used by the industry through the Boards or Technical Advisory Committees and Public-Private Partnerships. The role of the government is also crucial for the successful collaboration between the Vocational institutions and the industry. Some government cooperation policies need to be improved, like MoU and other programs to be implemented effectively. This role is essential to encourage both parties always to carry out the contents of the MoU or cooperation with a high commitment. Policies or MoUs should be easily understood and agreed upon to avoid the occurrence of excessive bureaucracy for both parties. According to (Purnamawati et al., 2019), a strategy that is believed to enhance the MoU of cooperation between vocational institutions and industry is by emphasizing 'Central Strategy.' The Central Strategy means rearranging undoubtedly the objectives, roles, and direction of the organization. Implementing the 'Consequence Strategy' is needed to encourage healthy competition to increase employee motivation and performance. The Customer strategy is also required, which focuses on being responsible for customers, and the 'Control Strategy' changes the organization's location and form of control. Finally, the 'Cultural Strategy' also needed to change the organization's work culture, consisting of habits, emotions, and psychology elements.

Besides that, to enhance the potential of this collaboration, the institute needs to invite industry workers to be part-time instructors to provide the industry's experience and skills to students (Ashari \& Rasul, 2014). They can also serve as advisors for developing vocational curricula in each institution. Students or teachers can be exposed to the latest technologies and adapt to the curriculum.

Empowering industry training programs is also a step that should be taken seriously. Implementing good industry training can produce quality graduates in line with industry requirements. The role of industry in providing quality training to students during industrial training will positively impact the industry itself. Students will be exposed to the latest technologies before entering the real working world. To empower industrial training programs, vocational institutions need some ideas for continuous quality improvement, such as providing appropriate training content (Jalani et al., 2016). According to (Nduro et al., 2015), to improve the quality of industrial training programs, a stakeholder's meeting could be organized rapidly to know what industries expect from interns.

Research on the factors that affect the cooperation between Vocational institutions and industry needs to be expanded because the collaboration between research institutions and industry is still limited. There are still many factors and constraints that need improvement to implement the cooperation program perfectly. Thus, various solutions will be featured as results of this research to the progress of the existing cooperation. In the 
meantime, researchers' suggestions should provide a framework for inspection or quality assurance and control in a variety of systems in the delivery of quality TVET (Moses, 2016).

To obtain a sustainable cooperative relation, the role of the government sector is indispensable. Support in terms of ideas, research, funding, and policy can contribute positively to this collaborative partnership. (Obwoge et al., 2013) have stated that the government sector should establish a policy whereby each Vocational institution must cooperate with the industry for every industry field to produce highly skilled graduates. Meanwhile, establishing the apprentice's board and Vocational Act is also required (Rashidi, 2013) to promote vocational institutions and industry collaboration.

Studies on collaboration between Vocational institutions and industries need to be increased as studies in this field are still limited (Moses, 2016). Therefore, the understanding between the two parties is still low, so this cooperation cannot be applied immaculately. Then, with increasing research can identify issues that should be emphasized for the successful collaboration between Vocational institutions with industry.

\section{Discussion}

Cooperation between Vocational institutions and the industry is not a new matter in education prospects. The main goal of this collaboration is to produce excellent graduates in theoretical knowledge and the field of skills. Thus, various cooperation programs with the industry have been established around the world to achieve the same goals. Getting the resources to improve the knowledge and skills is a priority of Vocational institutions to produce skilled graduates and meet the industry's requirements.

According to a study conducted in Kenya, many Vocational institutes have been developed to produce highly skilled workers (Obwoge et al., 2013). Several samples were taken to identify collaboration activities and focus among Vocational institutions and industry. On the industry side, $74.6 \%$ of activities focused on student attachments through industrial training programs, while $4.7 \%$ were registered to the partnership program. $4 \%$ of collaboration activities involve research collaboration, enhancing Instructor industrial experience, and equipment sharing. Only 3.3\% involve the staff exchange activities. On behalf of Vocational institutions, student industrial training is the main focus, with $100 \%$ implementation of collaboration between vocational institutions and industry. $8 \%$ is for staff exchange, $6 \%$ for instructor industrial equipment sharing experiences, and, finally, $4 \%$ for research collaboration and other programs (Asnorhisham, 2015). The researchers also noted that cooperation between Vocational institutions and the industry is still lacking compared to developed countries.

Tanzania has a strong collaboration between Vocational institutions and industry, particularly in the manufacturing and tourism industry. Collaboration between industry and education centers prioritizes dual apprentice systems, internship, and on-job training. Those collaborations create awareness of Vocational skills and skills, especially for the youth. (Moses, 2016). In India, there is an existing open system and Distance Learning (ODL), which will contribute to technical and vocational education (Miglani, 2018). However, it still requires strong co-operation with the industry for improvement. The ODL system collaboration with 
DEVELOPMENT

Vol. 11, No. 1, 2022, E-ISSN: 2226-6348 @ 2022 HRMARS

the industry will make the system more sustainable and supply skilled human resources according to industry requirements.

In Malaysia, to enhance students' skills in line with industry demand, the National Dual Training System (NDTS) was introduced in 2005. NDTS emphasizes aspects of competence in social factors such as self-control, responsibility, and soft skills. NDTS can also prepare students to deal with the natural working environment (Sauffie, 2014).

\section{Conclusion}

Cooperation between Vocational institutions and the industry is essential for curriculum development to produce quality graduates in hands-on skills and the development of soft skills. The industries and Training centers partnership is also very important to drive sustainable economic growth for a country. Various programs have been created throughout the world to produce a skilled workforce in current technology. It should be noted that every plan or framework designed will surely face various challenges and obstacles to its implementation. However, improvement measures have also been implemented to reduce the causes of the problem. Every plan implemented should align with the culture, the field of work, and the intended goals.

Among issues that have been identified and need to be emphasized is the mutual understanding between the two parties. Some terms and agreements need to be more comprehensive and transparent for both parties. Cultural disparities between the education system and industry need to be narrowed down so that cooperation can be implemented efficiently and effectively. Furthermore, collaboration is not implemented properly due to a lack of commitment from one of the parties involved. Bureaucratic factors are also issues that affect the implementation of such cooperation. The confidential problems are also one of the concerns faced by industries: some documents, technologies, or agreements that cannot be disclosed to others, especially trainee workers, to avoid the company secrecy being leaked to their competitors.

Financial allocation, learning tools, and the industry's commitments are essential things in developing skills-based education. Government cooperation policies need to be improved like MoU and other programs to be implemented effectively. This role is necessary to encourage both parties always to carry out the contents of the MoU or cooperation with a high commitment. Policies or MoUs should be easily understood and agreed upon to avoid excessive bureaucracy for both parties. The institute needs to invite industry workers to be part-time instructors to provide the industry's experience and skills to students and teachers to adapt to the new technologies in the curriculum. Next, empowering industrial training program implementation can produce quality graduates in line with industry requirements. Besides that, to attract the industry to collaborate, Vocational Institutions need to emphasize soft skills to students and not just technical knowledge or skills only.

\section{References}

Abu-Hamatteh, Z., Al-Amyan, M., \& Al-Azzam, F. (2008). Prospective Industrial linkage at Aqaba University College, Jordan. Journal of STEM Education: Innovations and Research, 9(3), 25-30. Retrieved from http://search.ebscohost.com/login.aspx?direct=true \&db=eric\&AN=EJ1096160\&scope= 
site\%0Ahttp://www.jstem.org/index.php?journal=JSTEM\&page=article\&op=view\&path $\% 5 B \% 5 D=1445$

Adam, S., Rasul, M. S., Yasin, R. M., Yahaya, N., \& Muridan, N. D. (2017). Effective elements of industry-training center collaboration in National Dual Training Systems ( NDTS ) Program. 7(11), 1200-1212. https://doi.org/10.6007/IJARBSS/v7-i11/3358

Ashari, Z. H. M., \& Rasul, M. S. (2014). They are determining the Issues and Concern in Malaysia' S Tvet Agency -Industry Engagement. 10th AASVET Conference 2014, 1-7.

Asnorhisham, M. (Disember, 2015). Isu pendekatan pengajaran kolaboratif terhadap pemulihan literasi Bahasa Melayu. In International Education Postgraduate Seminar 2015 (p. 208).

ElObeidy, A. A. (2016). The role of education and training in enhancing labour productivity in Arab countries in Africa. International Journal of Training and Development, 20(3), 238245. https://doi.org/10.1111/ijtd.12078

Forero, D. A., Lopez-Leon, S., González-Giraldo, Y., \& Bagos, P. G. (2019). Ten simple rules for carrying out and writing meta-analyses. PLOS Computational Biology, 15(5), e1006922. https://doi.org/10.1371/journal.pcbi.1006922

Jalani, J., Mashori, S., Norjali, R., \& Sadun, A. S. (2016). Preliminary investigation of the practicality of an industrial training for engineerign technology program-industries view preliminary investigation of the practicality of an industrial training for engineerign technology program - industries view. ARPN Journal of Engineering and Applied Sciences, 11(June 2016), 11.

Krishnamurthy, R., VandeCreek, L., Kaslow, N. J., Tazeau, Y. N., Miville, M. L., Kerns, R., ... Benton, S. A. (2004). Achieving competency in psychological assessment: Directions for education and training. Journal of Clinical Psychology, 60(7), 725-739. https://doi.org/10.1002/jclp.20010

Miglani, A., Awadhiya, A. K., Singh, N., Gowthaman, K., \& Kansal, G. (2018). Policy recommendations from employers for enhancing skills through ODL. Turkish Online Journal of Distance Education, 19(4), 64-75.

Moses, K. M. (2016). Improving the quality and competence of technical vocational education and training output through vocational school cooperation with industry: A case study of Uganda. AIP Conference Proceedings, 1778(2016). https://doi.org/10.1063/1.4965794

Nduro, K., Anderson, I. K., Peprah, J. A., \& Twenefour, F. B. K. (2015). Industrial training programmes of polytechnics in Ghana: The pertinent issues. World Journal of Education, 5(1). https://doi.org/10.5430/wje.v5n1p102

Nordin, A. S., Hassan, R., \& Ismail, A. (2014). Pembangunan profesionalisme tenaga pengajar di kolej vokasional. International Seminar on Technical and Vocational Education 2014, 2014(Tveis), 280-295.

Obwoge, M. E., Mwangi, S. M., Nyongesa, W. J., \& Lewis, T. (2013). Linking TVET Institutions and Industry in Kenya: Where Are We? Curriculum Inquiry, 37(4), 329-349. Retrieved from

http://search.ebscohost.com/login.aspx?direct=true \&db=eric\&AN=EJ780413\&site=eho st-live;\%5Cnhttp://dx.doi.org/10.1111/j.1467-873X.2007.00390.x

Purnamawati, \& Syahrul. (2018). School with business and industrial world. A Design of Partnership Model of Vocational High School with Business and Industrial World, 201(Aptekindo), 214-217.

Purnamawati, Syahrul, \& Yahya, M. (2019). Developing a partnership model of vocational high school with business and industrial world based core strategies. 1st International 
Conference on Advanced Multidisciplinary Research, 227(Icamr 2018), 261-264.

Raihan, M. A. (2014). Collaboration between TVET institutions and industries in Bangladesh to enhance employability skills. International Journal of Engineering and Technical Research (IJETR), 2(10), 50-55.

Rashidi, R. B. H. (2013). Evaluation of collaboration between public training institutions and private industries and its importance in improving the quality of training delivery in TVET in Malaysia. Evaluation of Collaboration between Public Training Institutions and Private Industries and Its Importance in Improving the Quality of Training Delivery in TVET in Malaysia, (1), 18. Retrieved from http://www.tvet-online.asia/issue1/rashidi_tvet1.pdf Sauffie, N. F. B. M. (2014). Technical and vocational education transformation in malaysia: Shaping the future leaders. Journal of Education and Practice, 6(22), 85-89. Retrieved from http://eric.ed.gov/?q=educational+leadership+in+TVET\&pr=on\&id=EJ1079588 